\title{
Lymphogranuloma venereum among men who have sex with men in the Netherlands: regional differences in testing rates lead to underestimation of the incidence, 2006-2012
}

N E Koper ${ }^{1}$, M A van der Sande ${ }^{1,2}$, H M Gotz 3 , F D Koedijk (femke.koedijk@rivm.nl)1, on behalf of the Dutch STI clinics ${ }^{4}$

1. Epidemiology and Surveillance Unit, Centre for Infectious Disease Control, National institute for Public Health and the Environment, Bilthoven, the Netherlands

2. Academic Medical Centre Utrecht, University of Utrecht, Utrecht, the Netherlands

3. Department of Infectious Disease Control, Rotterdam Rijnmond Public Health Service, Rotterdam, the Netherlands

4. The participants are listed at the end of the article

Citation style for this article:

Koper NE, van der Sande MA, Gotz HM, Koedijk FD, on behalf of the Dutch STI clinics. Lymphogranuloma venereum among men who have sex with men in the Netherlands: regional differences in testing rates lead to underestimation of the incidence, 2006-2012. Euro Surveill. 2013;18(34):pii=20561. Available online:

http://www.eurosurveillance.org/ViewArticle.aspx?Articleld=20561

Since 2003, an epidemic of lymphogranuloma venereum (LGV) has been ongoing in men who have sex with men (MSM) in Europe. Of 92,271 MSM consulting sexually transmitted disease (STI) clinics in the Netherlands between 2006 and 2011, 63,228 (68\%) were tested for anorectal Chlamydia infection, with $6,343(10 \%)$ positive diagnoses. In 4,776 of those $(75 \%)$, LGV testing was performed, with regional variation from $7 \%$ to $97 \%$. In total 414 LGV cases were diagnosed, a mean annual positivity rate of $8.7 \%$, decreasing from $14 \%$ in 2007 to $6 \%$ in 2011, but increasing to $13.1 \%$ during 2012 (184 new cases). Risk factors for LGV were human immunodeficiency virus (HIV) positivity (odds ratio $(\mathrm{OR})=4.1 ; 95 \%$ confidence interval $(\mathrm{Cl})$ : $3.2-5.3)$, STI symptoms $(O R=4.1$; 95\% Cl: 3.1-5.4), more than 50 sex partners in the past six months (OR=3.7; 95\% Cl: 1.1-12.4), older age (40-44 years: $\mathrm{OR}=2.1 ; 95 \% \mathrm{Cl}: 1.5-2.8$ ), no condom use $(\mathrm{OR}=2.2 ; 95 \% \mathrm{Cl}: 1.2-3.9)$ and homosexuality (as opposed to bisexuality; $\mathrm{OR}=2.2 ; 95 \% \mathrm{Cl}$ : 1.1-4.2). Regional differences in LGV testing rates limit national LGV surveillance, leading to an underestimation of the real incidence. Characteristics of MSM with LGV did not change over time, so existing prevention strategies should be intensified.

\section{Introduction}

Men who have sex with men (MSM) are generally considered to be at increased risk for a range of sexually transmitted infections (STIs), including gonorrhoea and human immunodeficiency virus (HIV) infection [1]. This is supported by the observation that in the Netherlands in $2010,19 \%$ of MSM attending an STI clinic were diagnosed with one or more STIs, compared with $12 \%$ of heterosexual attendees [1].
Since 2003, an epidemic of lymphogranuloma venereum (LGV) has been ongoing among MSM in Europe [2]. The first cases of the epidemic were reported in Rotterdam, the Netherlands [3,4]. Before 2003, the incidence of LGV in the Netherlands had been approximately five cases annually, and LGV was considered to be a rare tropical disease endemic in other areas of the world, including Africa, India, Asia and the Caribbean [5]. The 1,693 cases reported during this epidemic showed several similarities: they were all male, specifically MSM, over 25 years-old, and the majority $(80-100 \%)$ was HIV-positive [6]. After careful investigation of this first Dutch outbreak, sexual contacts of these patients were traced to Belgium, France, Germany and the United Kingdom [4], which could explain the rapid spread of the disease throughout Europe.

LGV is a bacterial infection caused by the L1, $\mathrm{L}_{2}$ or $\mathrm{L}_{3}$ serovars of the intracellular bacterium Chlamydia trachomatis [7]. C. trachomatis infection with serovars D to $\mathrm{K}$ is mostly associated with mild to asymptomatic infection. However, LGV is considered to be a more invasive infection that results in symptomatic infection in the majority of cases [8]. The ulcerative nature of LGV has been suggested to be associated with increased STI transmission, for example of HIV and other bloodborne infections such as hepatitis $C[3,7]$.

After the first cluster of LGV cases was reported in January 2003, enhanced surveillance of the disease was implemented in the Netherlands [9]. Increased awareness of the disease resulted in the development of a European guideline advising on control measures [10]. The two main recommended interventions were partner 
notification and monitoring patients until all symptoms have disappeared, to prevent further spread.

The primary guideline for LGV testing at STI clinics in the Netherlands was developed by the National Preparedness and Response Unit of the Dutch Centre for Infectious Disease Control $(\mathrm{Clb} / \mathrm{LCl})$ at the National Institute for Public Health and the Environment (RIVM) [11]. This guideline recommends LGV testing for all MSM presenting with clinical symptoms. Furthermore, the Dutch Society for Dermatology and Venereology (NVDV) published in 2005 their recommendation that LGV testing should be performed for all MSM with anorectal chlamydia [12]. The guideline developed by the NVDV is a broader second-line guideline, which may also be considered by STI clinics in addition to the RIVM guidelines. However, it is currently being discussed whether only HIV-positive MSM and MSM showing STI symptoms should be tested for LGV.

This study aims to provide an update on how the epidemic of LGV among MSM in the Netherlands developed over the period from January 2006 to December 2012, and its implications for current and future control policy, by analysing quantitative STI surveillance data.

\section{Methods}

\section{Study sample and design}

This study is a time-trend analysis of surveillance data, including data on MSM attending any STI clinic in the Netherlands between 1 January 2006 and 31 December 2011. MSM were defined as men who have sexual contacts either exclusively with men or with both men and women. The dataset contained 92,271 consultations by MSM in this time period, and data collection did not allow for identification of repeat visits of the same individual. In addition, preliminary data on LGV testing and diagnoses of the first half of $\mathbf{2 0 1 2}$ were included.

\section{Data collection}

At the STI clinics, STI consultations were conducted anonymously and reported to the RIVM facilitated by a web-based application called SOAP. For all clients, information on demographics and behavioural risks was collected by an interview with a nurse or medical doctor. Each STI consultation involved laboratory testing and medical examination. Clients were routinely tested for chlamydia, gonorrhoea, syphilis and HIV infection [1].

LGV diagnosis is a two-step process. First, samples obtained from clinic attendees were routinely tested for chlamydia. According to the Dutch guidelines, anorectal testing for chlamydia was performed based on reported risk behaviour and/or symptoms [11,12]. If the anorectal chlamydia test is positive, further testing for LGV serovars can be performed.
Data analysis

Characteristics of MSM were investigated by applying descriptive statistics. Within the group of MSM tested for LGV, chi-square testing was applied to investigate whether there was a significant association ( $p<0.05)$ between the characteristics and LGV test result.

Based on the dates of the consultations, time trends for the positivity rate for LGV were investigated. Positivity rates were obtained by calculating the proportion of LGV-positive cases among all MSM in whom LGV testing was performed. Furthermore, the proportion of anorectal chlamydia-positive MSM for whom LGV testing was performed was calculated to investigate whether there were geographical differences in testing practice. We followed the division of the Netherlands into eight different regions with one central STI clinic per region, as described in Vriend et al. [1].

Univariate logistic regression analysis was performed to select relevant variables to be included in multivariate logistic regression analysis for risk factors for LGV infection. Variables with a significance of p<0.20 were included in subsequent analyses. The effect of the variables was investigated for LGV-positive MSM compared with LGV-negative MSM. LGV-negative MSM were defined as MSM with an anorectal Chlamydia infection, but with a negative LGV test result. MSM with a negative anorectal chlamydia test were defined as anorectal chlamydia-negative MSM. MSM without an anorectal chlamydia test were defined as not anorectally tested MSM.

A backward stepwise approach was selected to investigate which variables were significant risk factors for LGV infection. For multivariate analysis, the confidence level for statistical significance was set at $p \leq 0.05$. To investigate time trends, these analyses were also performed after stratification by year. All statistical analyses were carried out using IBM SPSS Statistics 19.

In addition, a crude estimation was made to investigate how many cases could potentially be missed among the anorectal chlamydia-positive MSM for whom LGV testing was not performed. This estimation was made by extrapolating positivity rates for significant risk factors to the population of anorectal chlamydia-positive MSM for whom LGV testing was not performed. Differences in diagnostics and number of LGV patients between STI clinics were not taken into account in this estimation.

\section{Results}

\section{Study population}

In 63,228 of the 92,271 (69\%) consultations of MSM between 2006 and 2011, an anorectal Chlamydia infection was tested for, with 6,343 positive anorectal chlamydia diagnoses, a positivity rate of $10 \%$. In 4,776 of these 6,343 consultations (75\%), LGV testing was performed and between 2006 and 2011, 414 cases of LGV were diagnosed (Table 1). 
TABLE 1

Characteristics of MSM with an anorectal Chlamydia infection, MSM tested for LGV, MSM diagnosed with LGV and LGV positivity rate of MSM visiting an STI clinic in the Netherlands, 2006-2011 ( $\mathrm{n}=6,343)$

\begin{tabular}{|c|c|c|c|c|c|c|}
\hline & & \multirow{2}{*}{$\begin{array}{c}\text { Anorectal } \\
\text { CT-positive MSM } \\
\text { Number }\end{array}$} & \multirow{2}{*}{$\begin{array}{l}\text { MSM tested for } \\
\text { LGV } \\
\text { Number }\end{array}$} & \multicolumn{2}{|c|}{ LGV-positive MSM } & \multirow[t]{2}{*}{$p$ value } \\
\hline & & & & Number & $\%$ positive & \\
\hline \multicolumn{2}{|l|}{ Total } & 6,343 & 4,776 & 414 & 8.7 & \multirow{7}{*}{$<0.001$} \\
\hline \multirow{6}{*}{ Year of consultation } & 2006 & 572 & 342 & 34 & 9.9 & \\
\hline & 2007 & 710 & 464 & 65 & 14.0 & \\
\hline & 2008 & 1,061 & 772 & 98 & 12.7 & \\
\hline & 2009 & 1,082 & 867 & 82 & 9.5 & \\
\hline & 2010 & 1,381 & 1,136 & 66 & 5.8 & \\
\hline & 2011 & 1,537 & 1,195 & 69 & 5.8 & \\
\hline \multirow{4}{*}{ Age group ${ }^{a}$} & $\ll 35$ & 2,788 & 2,008 & 97 & 4.8 & \multirow{4}{*}{$<0.001$} \\
\hline & $35-39$ & 998 & 806 & 81 & 10.0 & \\
\hline & $40-44$ & 991 & 774 & 109 & 14.1 & \\
\hline & $>45$ & 1,565 & 1,188 & 127 & 10.7 & \\
\hline \multirow{8}{*}{ Origin ${ }^{b}$} & The Netherlands & 4,941 & 3,565 & 303 & 8.5 & \multirow{8}{*}{$<0.001$} \\
\hline & Turkey/Morocco & 69 & 58 & 2 & 3.4 & \\
\hline & Suriname/Antilles & 250 & 203 & 26 & 12.8 & \\
\hline & Eastern Europe & 148 & 108 & 5 & 4.6 & \\
\hline & Sub-Saharan Africa & 44 & 39 & 2 & 5.1 & \\
\hline & Middle and South America & 197 & 189 & 17 & 9.0 & \\
\hline & Asia & 202 & 177 & 5 & 2.8 & \\
\hline & Other/unknown & 492 & 437 & 54 & 12.4 & \\
\hline \multirow{3}{*}{ STI symptoms ${ }^{c}$} & No & 3,336 & 2,470 & 83 & 3.4 & \multirow{3}{*}{$<0.001$} \\
\hline & Yes & 1,900 & 1,568 & 244 & 15.6 & \\
\hline & Unknown/missing & 1,107 & 738 & 87 & 11.8 & \\
\hline \multirow{3}{*}{ Notified ${ }^{c}$} & No & 3,918 & 3,022 & 248 & 8.2 & \multirow{3}{*}{$<0.001$} \\
\hline & Yes & 1,315 & 1,006 & 76 & 7.6 & \\
\hline & Unknown/missing & 1,110 & 748 & 90 & 12.0 & \\
\hline \multirow{2}{*}{ Sexual preference } & Bisexual & 658 & 392 & 10 & 2.6 & \multirow{2}{*}{$<0.001$} \\
\hline & Homosexual & 5,685 & 4,384 & 404 & 9.2 & \\
\hline \multirow{3}{*}{ Intravenous drug use } & No/yes, ever & 6,140 & 4,616 & 401 & 8.7 & \\
\hline & Yes, in past six months & 20 & 18 & 5 & 27.8 & 0.007 \\
\hline & Unknown & 183 & 142 & 8 & 5.6 & \\
\hline & No & 6,154 & 4,541 & 408 & 8.8 & \\
\hline Commercial sex worker & Yes & 148 & 110 & 4 & 3.6 & 0.164 \\
\hline & Unknown & 41 & 25 & 2 & 8.0 & \\
\hline & No & 6,243 & 4,716 & 412 & 8.7 & \\
\hline $\begin{array}{l}\text { Client of commercial sex } \\
\text { worker }\end{array}$ & Yes & 59 & 34 & 0 & 0.0 & 0.193 \\
\hline & Unknown & 41 & 26 & 2 & 7.7 & \\
\hline & $0-1$ & 424 & 216 & 5 & 2.3 & \\
\hline Number of sexual & $2-5$ & 1,873 & 1,209 & 47 & 3.9 & \\
\hline partners in past six & $6-50$ & 1,726 & 1,287 & 108 & 8.4 & $<0.001$ \\
\hline months $^{d}$ & $\geq 51$ & 99 & 70 & 8 & 11.4 & \\
\hline & Unknown/missing & 2,221 & 1,994 & 246 & 12.3 & \\
\hline & No & 2,148 & 1,425 & 15 & 2.4 & \\
\hline $\begin{array}{l}\text { Condom use in last } \\
\text { sexual contact }\end{array}$ & Yes & 1,092 & 633 & 97 & 6.8 & $<0.001$ \\
\hline & Unknown/missing & 3,103 & 2718 & 302 & 11.1 & \\
\hline & No & 3,900 & 2,827 & 140 & 11.5 & \\
\hline History of STI infection ${ }^{f}$ & Yes & 1,647 & 1,222 & 191 & 6.8 & $<0.001$ \\
\hline & Unknown & 796 & 727 & 83 & 11.4 & \\
\hline & Negative & 3,466 & 2,510 & 96 & 3.8 & \\
\hline Previous HIV status & Positive & 1,833 & 1,574 & 292 & 18.6 & $<0.001$ \\
\hline & Unknown & 1,044 & 692 & 26 & 8.9 & \\
\hline & Gonorrhoea & 1,418 & 1,060 & 107 & 10.1 & 0.061 \\
\hline STI co-infections ${ }^{g}$ & Infectious syphilis & 398 & 292 & 37 & 12.7 & 0.012 \\
\hline & HIV (new infection) & 307 & 244 & 11 & 4.5 & 0.018 \\
\hline
\end{tabular}

CT: Chlamydia trachomatis; HIV: human immunodeficiency virus; LGV: lymphogranuloma venereum; MSM: men who have sex with men; STI: sexually transmitted infection.

a For one person, information on age was missing.

b Combination of two questions: self-defined origin (compulsory until 2010, voluntary in 2011) in which missing values for 2011 were filled with values for the new question: origin based on country of birth (voluntary in 2010, compulsory in 2011). Other/unknown: contained cases from other countries (in Europe) and cases with unknown origin.

c Optional question in 2007, compulsory since 2008.

d Optional question in 2006-09, compulsory question in 2010-11.

e Optional question 2006-2010, compulsory question in 2011.

$f$ Gonorrhoea, chlamydia or syphilis infection in the past two years.

g Only those STIs are presented for which every client was tested. 
Number of diagnoses $(n=598)$, tests performed $(n=6,181)$, and positivity rate for lymphogranuloma venereum, the Netherlands, January 2006-December 2012

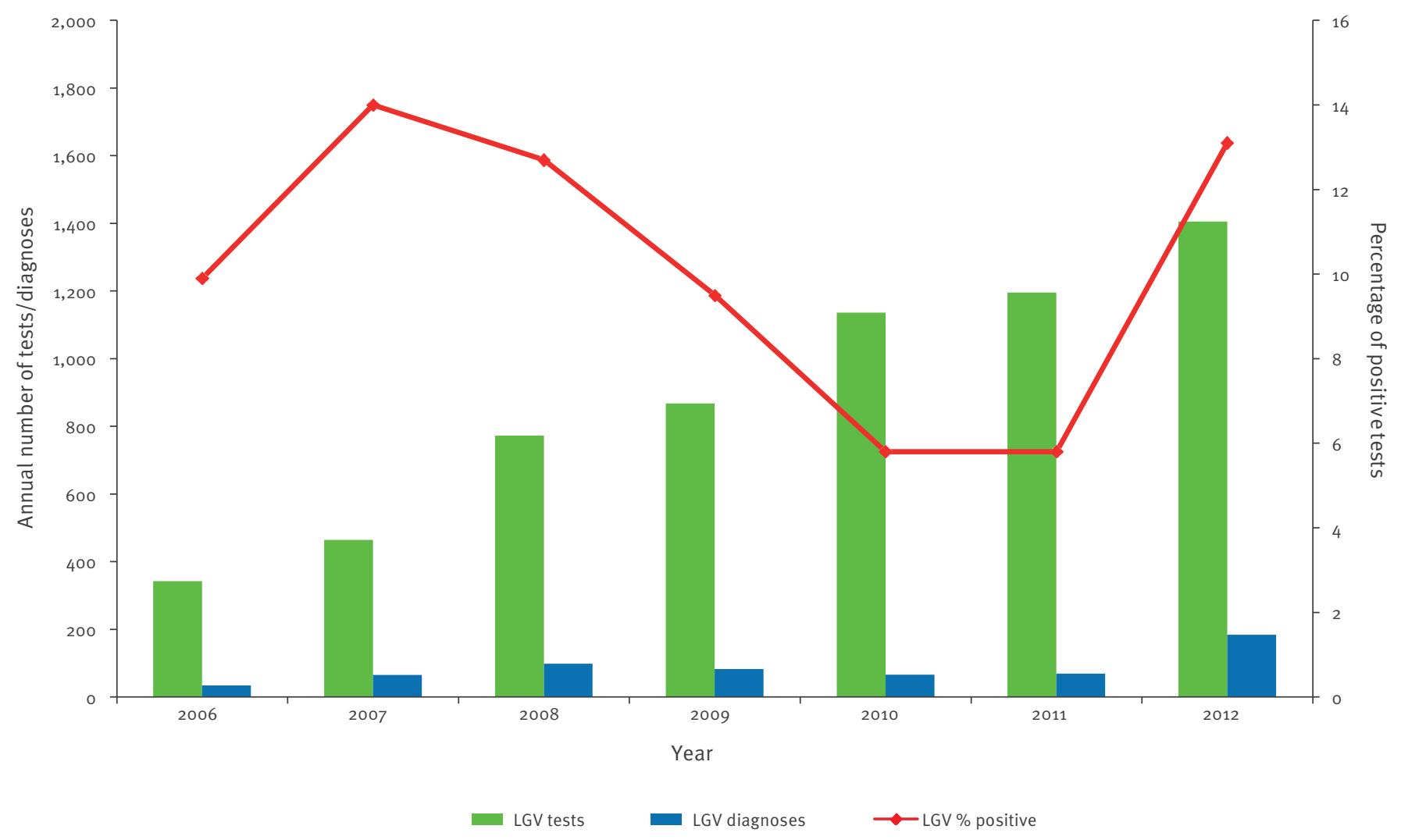

LGV: Lymphogranuloma venereum.

The annual number of reported LGV cases among MSM tested for LGV started with 34 in 2006, and in 2011, 69 cases were reported by the STI clinics (Figure 1). Over this period, the annual number of reported cases fluctuated. Recent data from 2012 showed that 184 LGV cases were diagnosed in 2012.

The main differences between LGV-negative and LGVpositive MSM were in age and HIV status. Among anorectal chlamydia-positive MSM and MSM tested for LGV, approximately $15 \%$ were 40 to 44 years-old, whereas $26.3 \%(n=109)$ of LGV cases belonged to this age group (p<0.001). Furthermore, among MSM who were tested for LGV, 33.0\% $(n=1,574)$ were HIV-positive, and among LGV cases, $70.5 \%(n=292)$ were HIV-positive ( $p<0.001)$. Analyses of the characteristics of LGV cases by year showed no significant trends (data not shown).

Overall, $75.3 \%(n=4,776)$ of all cases of anorectal chlamydia were tested for LGV (Table 1). In 2010 and 2011, these were $85.8 \%(n=1,136)$ and $82.5 \%(n=1,195)$ respectively. Figure 2 illustrates that LGV testing rates differed per region, ranging from $6.5 \%$ to $98.3 \%$.

\section{Positivity rate}

Over the period from 2006 to 2011 the overall positivity rate for LGV testing was $8.7 \%$ (Table 1). Since 2006 , the annual number of LGV tests performed has steadily increased from 342 in 2006 to 1,195 in 2011 (Figure 1). Until 2008, the increase in the number of tests was reflected in an increase in the number of LGV cases diagnosed. After 2008, the number of tests increased while the number of cases diagnosed did not, resulting in a decreasing positivity rate from 2007 onwards, with $6 \%$ in 2010 and 2011. In 2012, a rise in positivity rate was seen $(13.1 \%)$.

\section{Risk factors}

Risk factors for LGV infection were investigated using MSM who tested negative for LGV as the reference population (Table 2). The two risk factors for LGV infection with the highest odds ratios were HIV positivity $(\mathrm{OR}=4.1,95 \% \mathrm{Cl}: 3.2-5.3)$ and symptoms at the time of consultation $(\mathrm{OR}=4.1,95 \% \mathrm{Cl}: 3.1-5.3)$. Other identified risk factors for LGV were having had more than 50 sexual partners in the past six months (OR=3.7, 95\% $\mathrm{Cl}$ : 1.1-12.4), no condom use during last sexual contact (OR=2.2, 95\% Cl:1.2-3.9), homosexuality (as opposed to bisexuality; $\mathrm{OR}=\mathbf{2 . 2}, 95 \% \mathrm{Cl}: 1.1-4.2)$ and increasing age with a peak in the group aged 40-44 years $(\mathrm{OR}=2.1,95 \% \mathrm{Cl}: 1.5-2.8)$.

\section{Underestimation of cases}

By restricting the testing policy to a specific population of MSM positive for anorectal chlamydia, cases may be missed. Two strong risk factors identified in this 
Geographical differences in lymphogranuloma venereum testing rates among anorectal Chlamydia-positive men who have sex with men, the Netherlands, 2010-2011 $(n=6,343)$

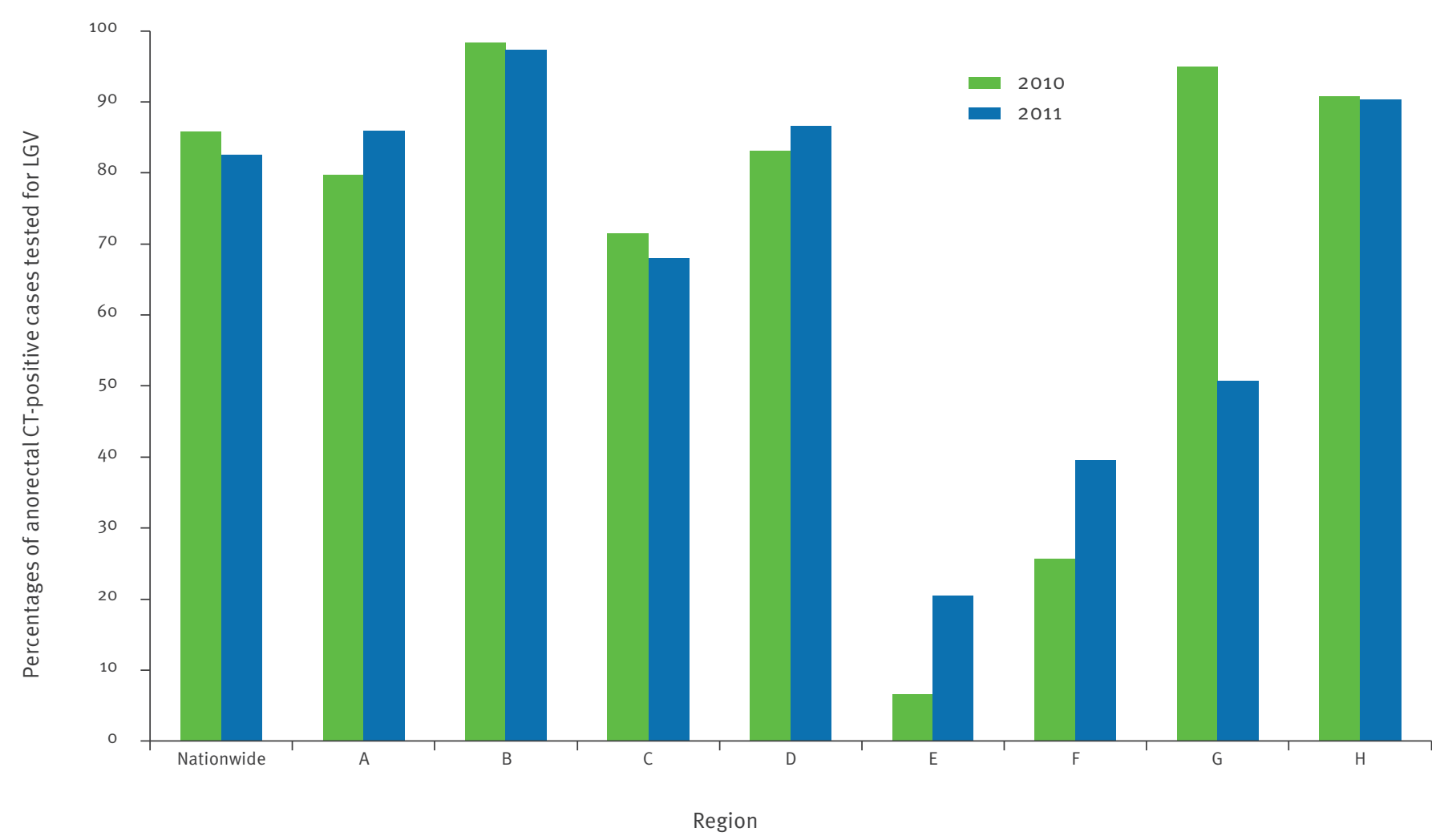

CT: Chlamydia trachomatis; LGV: lymphogranuloma venereum.

study were HIV positivity and clinical symptoms at the time of consultation $(O R=4.1)$. If the testing policy for LGV was restricted according to either one or both of these factors, this would result in an underestimation of the actual number of cases. In the period from 2007 to $2011,22.5 \%(n=87)$ of LGV cases were diagnosed among MSM who did not exhibit clinical symptoms, and $24.5 \%(n=95)$ of LGV cases were diagnosed among MSM who were HIV-negative (data on clinical was symptoms was not available before 2007). Moreover, in this period, $9.0 \%(n=35)$ of LGV cases were diagnosed among attendees who were neither HIV-positive nor exhibited clinical symptoms. Of the HIV-positive MSM among LGV cases, $21.8 \%(n=52)$ did not exhibit STI symptoms.

Combining data from 2010 and 2011, 2,719 cases of anorectal chlamydia were diagnosed among MSM. For $84.1 \%$ of these cases $(n=2,286)$, LGV testing was performed. We estimated that 27 cases of LGV could have been missed in this period. With a recorded combined incidence over these two years of 136 cases, this would imply an underdiagnosis of $19.9 \%$.

\section{Discussion}

The results indicate that while the incidence of LGV fluctuated during the period from 2006 to 2011, there was no clear increasing or decreasing trend. However, the reported incidence remained consistently higher than before the first outbreak in 2003 [5]. Data from 2012 showed a further increased number of reported LGV cases as well as a higher rate of positive tests. Since the proportion of MSM with an anorectal chlamydia infection tested for LGV remained stable over time (around 75\%), the increase seems to be a real increase in positivity rate, rather than an increase due to more diagnostic testing. Although it remains unknown how the epidemic will develop in the future, current data underline the importance of active testing and continuous monitoring of the infection. After 2005, the annual number of LGV tests increased sharply, maybe due to widespread uptake and implementation of the RIVM and NVDV guidelines by municipal health centres. Until 2008, the number of LGV diagnoses also showed a slight increase, suggesting that implementation of these guidelines had improved case detection. It is therefore worrisome that in several regions LGV testing rates were low among MSM positive for anorectal chlamydia. This not only hampers national surveillance, but also detection and treatment of LGV infections.

The present study showed that older age (>40 years), clinical symptoms, sexual preference, having many partners in the past six months (>50), not using condoms, and HIV positivity remained the main risk 
TABLE 2

Risk factors for LGV infection among MSM tested positive for LGV compared to MSM with a non-LGV anorectal Chlamydia infection at an STI clinic in the Netherlands, 2006-2011

\begin{tabular}{|c|c|c|c|c|c|c|}
\hline \multirow{3}{*}{ Risk factors } & & \multirow{3}{*}{ Total Number } & \multicolumn{4}{|c|}{ LGV-positive MSM } \\
\hline & & & \multicolumn{3}{|c|}{ Univariate } & \multirow{2}{*}{$\begin{array}{l}\text { Multivariate } \\
\text { OR }(95 \% \mathrm{Cl})\end{array}$} \\
\hline & & & Number & OR $(95 \% \mathrm{Cl})$ & $p$ value & \\
\hline \multicolumn{2}{|l|}{ Total } & 4,776 & 414 & & & \\
\hline \multirow{6}{*}{ Year } & 2006 & 342 & 34 & 1.0 & \multirow{6}{*}{$<0.001$} & 1.0 \\
\hline & 2007 & 464 & 65 & $1.5(1.0-2.3)$ & & $1.1(0.7-1.7)$ \\
\hline & 2008 & 772 & 98 & $1.3(0.9-2.0)$ & & $0.7(0.3-1.7)$ \\
\hline & 2009 & 867 & 82 & $1.0(0.6-1.4)$ & & $0.6(0.2-1.3)$ \\
\hline & 2010 & 1,136 & 66 & $0.6(0.4-0.9)$ & & $0.3(0.1-0.8)$ \\
\hline & 2011 & 1,195 & 69 & $0.6(0.4-0.9)$ & & $0.3(0.1-0.8)$ \\
\hline \multirow{4}{*}{ Age group } & $<35$ & 2,008 & 97 & 1.0 & \multirow{4}{*}{$<0.001$} & 1.0 \\
\hline & $35-39$ & 806 & 81 & $2.2(1.6-3.0)$ & & $1.4(1.0-2.0)$ \\
\hline & $40-44$ & 774 & 109 & $3.2(2.4-4.3)$ & & $2.1(1.5-2.8)$ \\
\hline & $\geq 45$ & 1,188 & 127 & $2.4(1.8-3.1)$ & & $1.8(1.4-2.4)$ \\
\hline \multirow{8}{*}{ Origin $^{a}$} & The Netherlands & 3,565 & 303 & 1.0 & \multirow{8}{*}{$<0.001$} & \multirow{8}{*}{ NS } \\
\hline & Turkey/Morocco & 58 & 2 & $0.4(0.1-1.6)$ & & \\
\hline & Suriname/Antilles & 203 & 26 & $1.6(1.0-2.4)$ & & \\
\hline & Eastern Europe & 108 & 5 & $0.5(0.2-1.3)$ & & \\
\hline & Sub-Saharan Africa & 39 & 2 & $0.6(0.1-2.4)$ & & \\
\hline & Middle and South America & 189 & 17 & $1.1(0.6-1.8)$ & & \\
\hline & Asia & 177 & 5 & $0.3(0.1-0.8)$ & & \\
\hline & Other/unknown & 437 & 54 & $1.5(1.1-2.1)$ & & \\
\hline \multirow{3}{*}{ STI symptoms ${ }^{b}$} & No & 2,470 & 83 & 1.0 & \multirow{3}{*}{$<0.001$} & 1.0 \\
\hline & Yes & 1,568 & 244 & $5.3(4.1-6.9)$ & & $4.1(3.1-5.3)$ \\
\hline & Unknown/missing & 738 & 87 & $3.8(2.8-5.3)$ & & $1.7(0.8-3.7)$ \\
\hline \multirow{3}{*}{ Notified ${ }^{b}$} & No & 3,022 & 248 & 1.0 & \multirow{3}{*}{0.002} & \multirow{3}{*}{ NS } \\
\hline & Yes & 1,006 & 76 & $0.9(0.7-1.2)$ & & \\
\hline & Unknown/missing & 748 & 90 & $1.5(1.2-2.0)$ & & \\
\hline \multirow{2}{*}{ Sexual preference } & Bisexual & 392 & 10 & 1.0 & & 1.0 \\
\hline & Homosexual & 4,384 & 404 & $3.9(2.1-7.3)$ & $<0.001$ & $2.2(1.1-4.2)$ \\
\hline & No/yes,ever & 4,616 & 401 & 1.0 & & \\
\hline Intravenous drug use & Yes, past six months & 18 & 5 & $4.0(1.4-11.4)$ & 0.025 & NS \\
\hline & Unknown & 142 & 8 & $0.6(0.3-1.3)$ & & \\
\hline & No & 4,641 & 408 & 1.0 & & \\
\hline $\begin{array}{l}\text { Commercial sex } \\
\text { worker }\end{array}$ & \begin{tabular}{|l|} 
Yes \\
\end{tabular} & 110 & 4 & $0.4(0.1-1.1)$ & 0.104 & NS \\
\hline & Unknown & 25 & 2 & $0.9(0.2-3.8)$ & & \\
\hline & No & 4,716 & 412 & 1.0 & & \\
\hline $\begin{array}{l}\text { Client of commercial } \\
\text { sex worker }\end{array}$ & Yes & 34 & 0 & 0.0 & 0.044 & NS \\
\hline & Unknown & 26 & 2 & $0.9(0.2-3.7)$ & & \\
\hline & $0-1$ & 216 & 5 & 1.0 & & 1.0 \\
\hline Number of sexual & $2-5$ & 1,209 & 47 & $1.7(0.7-4.3)$ & & $1.3(0.5-3.4)$ \\
\hline partners in past six & $6-50$ & 1,287 & 108 & $3.9(1.6-9.6)$ & $<0.001$ & $2.4(0.9-6.2)$ \\
\hline months ${ }^{\mathrm{c}}$ & $>50$ & 70 & 8 & $5.5(1.7-17.2)$ & & $3.7(1.1-12.4)$ \\
\hline & Unknown/missing & 1,994 & 246 & $5.9(2.4-14.6)$ & & $1.8(0.6-4.9)$ \\
\hline & Yes & 633 & 15 & 1.0 & & 1.0 \\
\hline Condom use in last & No & 1,425 & 97 & $3.0(1.7-5.2)$ & $<0.001$ & $2.2(1.2-3.9)$ \\
\hline & Unknown/missing & 2,718 & 302 & $5.2(3.0-8.7)$ & & $2.4(1.3-4.3)$ \\
\hline & No & 2,827 & 191 & 1.0 & & \\
\hline $\begin{array}{l}\text { History of STI } \\
\text { infection }\end{array}$ & Yes & 1,222 & 140 & $1.8(1.4-2.2)$ & $<0.001$ & NS \\
\hline & Unknown & 727 & 83 & $1.8(1.4-2.3)$ & & \\
\hline & Negative & 2,510 & 95 & 1.0 & & 1.0 \\
\hline Previous HIV status & Positive & 1,574 & 292 & $5.8(4.6-7.4)$ & $<0.001$ & $4.1(3.2-5.3)$ \\
\hline & Unknown & 692 & 27 & $1.0(0.7-1.6)$ & & $0.9(0.6-1.5)$ \\
\hline
\end{tabular}

$\mathrm{Cl}$ : confidence interval; HIV: human immunodeficiency virus; LGV: lymphogranuloma venereum; MSM: men who have sex with men; NS: not significant; OR: odds ratio; STI: sexually transmitted infection.

a Combination of two questions: self-defined origin (compulsory until 2010, voluntary in 2011) in which missing values for 2011 were filled with values for the new question: origin based on country of birth (voluntary in 2010, compulsory in 2011). Other/unknown: contained cases from other countries (in Europe) and cases with unknown origin.

${ }^{b}$ Optional question in 2006-07, compulsory since 2008.

${ }^{\mathrm{c}}$ Optional question in 2006-09, compulsory question in 2010-11.

${ }^{\mathrm{d}}$ Optional question in 2006-10, compulsory question in 2011.

e Gonorrhoea, chlamydia or syphilis in the past two years. Optional question 2006-07, compulsory since 2008. 
factors for LGV infection. These findings are similar to previous studies in which the majority of LGV infections were symptomatic, contrary to infection with other C. trachomatis serovars [13,14], and in which HIV seropositivity was a strong risk factor for infection $[15,16]$. Taken together, these observations suggest that LGV infection is still primarily located in a specific population.

That the two most used guidelines for LGV diagnosis and treatment at Dutch STI clinics recommend different testing policies for LGV, can have caused the diverging testing policies observed, which may have resulted in an underdiagnosis. As shown in the present study, restricting the testing policy according to, for example, the risk factors of showing symptoms and HIV positivity results in underdiagnosis. However, health benefits gained by increased detection will always need to be weighed against the costs for such testing. Additional research is needed into the consequences of a certain degree of underdiagnosis resulting from a restricted testing policy in the Netherlands.

In particular, it is not known whether a shorter treatment regimen would be sufficient to treat asymptomatic LGV infections. All people attending Dutch STI clinics are routinely tested for chlamydia. Since LGV is caused by $C$. trachomatis L serovars, cases are already prescribed treatment for this infection. The standard treatment regimen for anorectal chlamydia is one week of doxycycline. If the standard treatment regimen for non-LGV serovars were sufficient to treat asymptomatic LGV infections, the focus could shift towards the detection of symptomatic infections requiring additional treatment and the impact of the resulting underdiagnosis on the health situation in the Netherlands would be reduced.

STI surveillance is instrumental in monitoring the disease situation and contributes to the evaluation of implemented control strategies. Currently, STI clinics can prioritise their policy according to the local situation. This became evident by investigating LGV test rates for anorectal chlamydia-positive MSM in different regions, and was also evident in conversations with experts in the field. Different regions applied different testing criteria, and a consequence may be that national trends identified by surveillance are distorted and opportunities to interrupt transmission were missed. Furthermore, different guidelines provide different advice. Attempts to harmonise different guidelines are ongoing. A new version of the secondary care guideline is currently in development and is expected to be published at the end of 2013 .

Since the start of the epidemic of LGV in 2003, the infection has remained limited to the MSM population. Spread of the infection to the general population, for example through bisexual MSM to heterosexual women, could be an important risk. There have recently been reports describing cases of rectal and bubonic LGV in women $[17,18]$. These reports indicate that expansion of LGV infection to other populations remains a realistic possibility. Therefore, it is important to remain vigilant for LGV infections also in heterosexual men and women with anorectal Chlamydia infections. Taken together, our results indicate that on the one hand, LGV mainly occurs in a specific population of MSM and it is only rarely observed among heterosexual males and females. On the other hand, it remains important to prevent and treat LGV in heterosexual men and women. Surveillance of these populations may allow to detect an expansion of the infection at an early stage.

A limitation of the present study is that LGV is not a notifiable disease in the Netherlands. Only data collected during STI consultations at STI clinics were available. However, reports from experts in the field suggest that a substantial proportion of LGV cases may be diagnosed at other sources of care such as hospitals. Another limitation is that the study was based on routinely collected surveillance data. Previous research shows that specific high-risk behaviour is an important risk factor for LGV infection [8]. Therefore, additional research could be performed to investigate in more detail which risk behaviours are risk factors for LGV infection among MSM in the Netherlands. If specific sexual practices result in increased risk, targeted prevention strategies could be developed.

\section{Conclusion}

Since LGV emerged as an STI among MSM in 2003, the incidence has been fluctuating around a level consistently higher than before the first outbreak. Over time, the infection has affected the same population as the one in which it originally emerged. Furthermore, recent case reports describe cases of LGV among women, and data for the first half of 2012 showed again an increased number of reported cases of LGV. Taken together, these observations underline the importance of tracing and monitoring the infection by strengthening and harmonising LGV diagnostic testing among MSM who are positive for anorectal chlamydia.

\section{Dutch STI clinics}

A van Daal (East), AP van Leeuwen (North-Holland Flevoland), F de Groot (North), AM Niekamp (Limburg), M Langevoort (Utrecht), AM van Camerijk (South-Holland North), J van de Sande (Zeeland-Brabant), V Wieërs (South-Holland South)

\section{Acknowledgements}

The authors would like to thank all experts who were consulted for taking the time to participate in this project and for providing their expert views on the topic. In particular we would like to thank Jean-Marie Brand and Harry van Kruchten for their input. 


\section{References}

1. Vriend HJ, Koedijk FD, van den Broek IV, van Veen MG, Op de Coul EL, van Sighem Al, et al. Sexually transmitted infections, including HIV, in the Netherlands in 2010. Bilthoven: Centre for Infectious Disease Control, National Institute for Public Health and the Environment; 2011. Report No.: 210261009/2011. Available from: http://www.rivm.nl/bibliotheek/ rapporten/210261009.pdf

2. Stary G, Stary A. Lymphogranuloma venereum outbreak in Europe. J Dtsch Dermatol Ges. 2008;6(11):935-40. http://dx.doi.org/10.1111/j.1610-0387.2008.06742_supp.x. PMid:18992036.

3. Gotz HM, van Doornum G, Niesters HG, den Hollander JG, Thio $\mathrm{HB}$, de Zwart $\mathrm{O}$. A cluster of acute hepatitis $\mathrm{C}$ virus infection among men who have sex with men-results from contact tracing and public health implications. AIDS. 2005;19(9):96974 . http://dx.doi.org/10.1097/01.aids.0000171412.6136o.f8. PMid:15905679.

4. Nieuwenhuis RF, Ossewaarde JM, Götz HM, Dees J, Thio HB, Thomeer MG, et al. Resurgence of lymphogranuloma venereum in Western Europe: an outbreak of Chlamydia trachomatis serovar 12 proctitis in The Netherlands among men who have sex with men. Clin Infect Dis. 2004;39(7):996-1003. http:// dx.doi.org/10.1086/423966. PMid:15472852.

5. Centers for Disease Control and Prevention (CDC). Lymphogranuloma venereum among men who have sex with men-Netherlands, 2003-2004. MMWR Morb Mortal Wkly Rep. 2004;53(42):985-8. PMid:15514580.

6. Savage EJ, van de Laar MJ, Gallay A, van der Sande M, Hamouda 0 , Sasse A, et al. Lymphogranuloma venereum in Europe, 2003-2008. Euro Surveill. 2009;14(48):pii=19428. Available from: http://www.eurosurveillance.org/ViewArticle. aspx?Articleld $=19428$

7. Martin-Iguacel R, Llibre JM, Nielsen H, Heras E, Matas L, Lugo $R$, et al. Lymphogranuloma venereum proctocolitis: a silent endemic disease in men who have sex with men in industrialised countries. Eur J Clin Microbiol Infect Dis. 2010;29(8):917-25.

http://dx.doi.org/10.1007/s10096-010-0959-2.

PMid:20509036.

8. de Vries HJ, van der Bij AK, Fennema JS, Smit C, de Wolf F, Prins $M$, et al. Lymphogranuloma venereum proctitis in men who have sex with men is associated with anal enema use and high-risk behavior. Sex Transm Dis. 2008;35(2):203-8. http:// dx.doi.org/10.1097/OLQ.ob013e31815abb08. PMid:18091565.

9. van de Laar MJ, de Boer IM, Koedijk FD, Op de Coul EL. HIV and Sexually Transmitted Infections in the Netherlands in 2004. An update: November 2005. Bilthoven: Surveillance Unit of STI and HIV/AIDS, Centre of Infectious Diseases Epidemiology, National Institute for Public Health and the Environment; 2005 . Report No.: RIVM report 441100022. Available from: http://rivm.openrepository.com/rivm/ bitstream/10029/7354/1/441100022.pdf

10. de Vries HJ, Morre SA, White JA, Moi H. European guideline for the management of lymphogranuloma venereum, 2010. Int J STD AIDS. 2010;21(8):533-6. http://dx.doi.org/10.1258/ ijsa.2010.010238. PMid:20975083.

11. National Coordination Centre for Outbreak Management (LCI). Guideline - Urogenitale Chlamydia trachomatis-infectie en lymfogranuloma venereum, 2009. [ $\mathrm{LCl}$-guideline Chlamydia trachomatis and lymphogranuloma venereum]. Bilthoven: National Insitute of Public Health and the Environment; 2011. Dutch. Available from: http://www.rivm.nl/dsresource?objectid =rivmp:23571\&type $=$ org \&disposition $=$ inline

12. Nederlandse Vereniging voor Dermatologie en Venereologie (NVDV). LGV Richtlijn plus stroomdiagram. [LGV Directive plus flowchart ]. Amsterdam: NVDV; 2011 [Accessed: 27 Feb 2012]; Dutch. Available from: http://www.soaaids-professionals.nl/ medische_richtlijnen/lgv_richtlijn

13. Annan NT, Sullivan AK, Nori A, Naydenova P, Alexander S, McKenna A, et al. Rectal chlamydia-a reservoir of undiagnosed infection in men who have sex with men. Sex Transm Infect. 2009;85(3):176-79. http://dx.doi.org/10.1136/sti.2008.031773. PMid:19176570.

14. Tinmouth J, Gilmour MW, Kovacs C, Kropp R, Mitterni L, Rachlis $A$, et al. Is there a reservoir of sub-clinical lymphogranuloma venereum and non-LGV Chlamydia trachomatis infection in men who have sex with men? Int J STD AIDS. 2008;19(12):805-9. http://dx.doi.org/10.1258/ijsa.2008.008260. PMid:19050208.

15. Ronn MM, Ward $H$. The association between lymphogranuloma venereum and HIV among men who have sex with men: systematic review and meta-analysis. BMC Infect Dis. 2011;11:70. http://dx.doi.org/10.1186/1471-2334-11-70. PMid:21418569. PMCid:PMC3070636.
16. van der Bij AK, Spaargaren J, Morre SA, Fennema HS, Mindel A, Coutinho RA, et al. Diagnostic and clinical implications of anorectal lymphogranuloma venereum in men who have sex with men: a retrospective case-control study. Clin Infect Dis. 2006;42(2):186-194. http://dx.doi.org/10.1086/498904. PMid:16355328.

17. Peuchant O, Baldit C, Le Roy C, Trombert-Paolantoni S, Clerc $M$, Bébéar C, et al. First case of Chlamydia trachomatis L2b proctitis in a woman. Clin Microbiol Infect. 2011;17(12):E213. http://dx.doi.org/10.1111/j.1469-0691.2011.03661.x. PMid:21951622.

18. Verweij SP, Ouburg $S$, de Vries $H$, Morré SA, van Ginkel CI, Bos $\mathrm{H}$, et al. The first case record of a female patient with bubonic lymphogranuloma venereum (LGV), serovariant L2b. Sex Transm Infect. 2012;88(5):346-7. http://dx.doi.org/10.1136/ sextrans-2011-050298. PMid:22363020. 